\title{
A COMPARATIVE INSTITUTIONAL APPROACH TO LAW AND LEGAL INSTITUTIONS
}

\author{
George Barker*
}

\section{Introduction}

The last ten years in New Zealand are widely recognised to have seen a revolution in economic policy and a transformation of the New Zealand economy. What is less widely understood is that the last ten years have in conjunction, and even at root, also involved a revolution in legal thought and analysis. This revolution in turn was made possible by significant advances that were made in the economic analysis of organisations and institutions, and which occurred over a longer period covering the last twenty to thirty years.

This new kind of so-called institutional economics can play a much greater role in the analysis of law, and can provide insights on the way people organise their private affairs across a wide front. ${ }^{1}$ This approach has already enriched and complemented the more strictly legal or "black letter" approach to law often taught in law schools, and is likely to continue to do so.

The legal profession in New Zealand however appears to have been slow to appreciate this fundamental change in thought and its implications for how they do business. The fact that this may be changing is suggested by the recent formation of the Law and Economic Association of New Zealand and the appearance of greater "economic content" in the judgments of the higher courts.

* DPhil (Oxon), MA (Hons), BA/LLB. Visiting Research Fellow, Institute of Policy Studies, Victoria University of Wellington and Chief Analyst The New Zealand Treasury. The views expressed are solely those of the author and do not necessarily reflect the views of his employers.

1 Thus it can encompass not only the analysis of commonly accepted economic institutions such as for profit firms and markets, but also voluntary organisations and the family. On the latter see for example R Pollak "A Transaction Costs Approach to Families and Households" (1985) 23 Journal of Economic Literature, 581. 
This paper seeks to bring the main elements of this new economic approach to law and policy to a wider legal audience. It seeks to review the main features of the recent and significant advances that have been made in the economic analysis of organisations and institutions over the last 20 to 30 years. The emphasis is on developments in the theoretical literature.

A key characteristic of this new approach is a greater emphasis on positive analysis, ${ }^{2}$ with the focus being on the nature and role of institutions ${ }^{3}$ in influencing individual decision making and therefore key economic and social outcomes over time. In this new approach no institution is expected to be perfect, nor perform equally well in all circumstances, nor perform as well for all time. Instead the performance of all institutions is subject to review, with performance judged relative to the performance of well elaborated real world alternative institutional options, given a clear set of objectives (eg justice, fairness, economic growth, freedom etc).

This approach attracted considerable attention in the 1980's in light of evidence that for a long period New Zealand's institutions had failed to meet the purposes for which they were established. The need to identify the reasons why, and what could be done about it was reinforced by the small open economy status of New Zealand. The country could not continue underperforming economically relative to other countries without facing the inevitable flight of capital, people and demand for outputs and services to better shores.

The paper is divided into five sections. The next section discusses the fundamental factors which have to be recognised as constraints on the ability to secure an ideal society. The problem then is one of identifying methods of social organisation that overcome or minimise the effect of these constraints, not the pursuit of options that assume them away. The third section of this paper discusses how private arrangements seek to overcome these constraints and the limits to their success. The fourth section discusses the role of the state in alleviating or overcoming problems with private solutions. A major theme of this section is the need to recognise that the state is not an omniscient and omnicompetent solver of social problems, but rather is subject to largely the same pitfalls that face private solutions to social problems, and other ones as well. The concluding section attempts to identify the

2 Or theoretical and empirical analysis of the way the world is as opposed to purely normative analysis of how it ought to be.

3 An institution can be defined as a set of collectively defined rules and sanctions both both formal and informal. John Commons defined an institution as "collective action in control of individual action". J R Commons The Economics of Collective Action (University of Wisconsin Press, Madison, 1970). North defines an institution as "the humanly devised constraints that structure political, economic and social interaction. They consist of both informal constraints (sanctions, taboos, customs, traditions and codes of conduct) and formal rules (constitutions, laws, property rights). (D North "Institutions" (1991) 5 Journal of Economic Perspectives 97.) 
key factors that need to be considered in comparing alternative means for achieving social goals.

\section{Constraints on the Achievement of Social Goals}

The basic constraint a society faces is the scarcity of resources (both physical and human) relative to the demands that can be placed upon them. There is a need to use physical and human resources efficiently, to make them go further, and to ensure that the uses to which they are allocated are those that are most highly valued. Scarcity then is the most fundamental constraint of all. It implies the need to find means to reconcile the demands of different claimants for the use of scarce resources. This process needs to ensure that resources are not wasted, and that they are employed in their most socially valued use.

Moreover we live in an interdependent world. Scarcity of resources in itself is a major source of such interdependencies. One person's use of a resource is likely to impact on another person either beneficially or detrimentally. Society needs to find methods of organisation that ensure interdependencies among individuals are resolved in a way that takes account of the welfare of all those affected.

A further constraint on the effective achievement of social goals is uncertainty. Uncertainty about the future and about the consequences of certain actions derives from what may be called the bounded rationality of individuals and the inevitability of complexity and change. Bounded rationality ${ }^{4}$ is the inability of humans to comprehend fully the nature of their environment, to anticipate or devise strategies to cope with change and to communicate effectively with each other. If individuals could fully anticipate and understand the network of causes and effects that exist, planning, both private and public, would be a relatively simple task. The future could be anticipated, and shaped, or strategies to cope with inescapable occurrences devised. Given the existence of bounded rationality, people must plan on the basis of a largely uncertain future, and they are forced to adapt to change and adopt strategies that minimise risks. Uncertainty then becomes something to be managed, never eliminated.

4 The development of this concept is most associated with H A Simon Models of Man (John Wiley \& Sons, New York, 1957). 
Beyond the problem of bounded rationality there is the problem of obtaining information. ${ }^{5}$ People may have the ability to make correct judgments but unless they have access to information, they will simply be unable to exercise their judgment. The acquisition of information involves costs, it is not free and for this reason it is also valuable. It is therefore something to be searched out, bought and produced. As with other scarce resources however, trade-offs have to be made. There is always some point at which it ceases to be economic to search for more information about problems or solutions. The benefits from further pursuing information need to be weighed against the costs.

A final constraint on our ability to achieve social goals is that individuals do not always have the purest or most saintly of motivations. Individuals are at least in part motivated by a concern for themselves. People thus have opportunistic tendencies. ${ }^{6}$ The organisation of society towards the achievement of social goals would be immensely easier if individuals were always generous, altruistic, honest and forgiving. When they are selfish, jealous, deceptive and spiteful then the costs of social organisation are raised. Individuals will therefore face difficulties in interacting and will need to protect themselves against the opportunism of others. The appropriate response to this problem is not to assume people ought to be different rather it is to devise means of organisation that limit the adverse consequences of opportunistic tendencies.

The problem of opportunism can be understood as a subset or manifestation of a more general problem - the problem of ensuring that individuals face incentives that align their interests with those of others. ${ }^{7}$ It is a problem fundamental to social organisation. How can people's incentives be aligned so that for instance shirking at the workplace, or uncooperative behaviour or white collar crime, or neglect of scarce resources is reduced?

5 Seminal work on the economics of information includes: G J Stigler "The Economics of Information" (1961) 69 Journal of Political Economy, 213; K Arrow "Limited Knowledge and Economic Analysis" (1974) 64 American Economic Review 1; A Alchian and H Demsetz "Production, Information Costs, and Economic Organisation" (1972) 62 American Economic Review, 777; GA Akerlof "The Market for Lemons: Quantity Uncertainty and the Market Mechanism" (1970) 84 Quarterly Journal of Economics 488; and A M Spence "Job Market Signalling" (1976) 87 Quarterly Journal of Economics 355.

6 Oliver E Williamson is best know for emphasising this condition in the economic analysis of organisations: for which see O E Williamson Markets and Heirarchies: Analysis and Antitrust Implications (Free Press, New York, 1975); and OE Williamson The Economic Institutions of Capitalism (Free Press, New York 1985).

7 A key early part of the literature focusing on this problem was principal agent theory. The term principal-agent problem is due to S Ross "The economic theory of agency: the principals problem" (1973) 63 American Economic Review 134. For an early review see J W Pratt and R J Zeckhauser (eds) Principles and Agents: The Structure of Business (Harvard University Press, Boston, 1985). 
In combination, these problems of scarcity, interdependence, uncertainty (or bounded rationality), the costs of information, and the problem of opportunism (or incentives) make social organisation towards desired goals an immensely difficult task. There will therefore be significant costs in social and economic interaction that may be generally described as transactions costs. The fundamental problem then is to discover methods of social organisation that relax or minimise these constraints in order to most efficiently marshall the activities of individuals towards common or consistent ends. To ignore these problems is to ignore the fundamental issues in social organisation. In the next section we discuss the way in which private arrangements evolve to cope with these problems.

\section{The Role and Limits of Private Arrangements}

This section seeks to interpret many of our institutions, organisations and practices as means by which individuals separately and as groups seek to adapt to the basic problems underlying social organisation pointed to above.

\section{A The Role of Exchange}

Interdependencies and the problem of scarcity are in fact resolved most frequently through private parties voluntarily contracting with each other to reconcile their interests. An example of voluntary contracting overcoming interdependencies is when neighbours come to an agreement about the nature of the fence that should separate their properties. Through voluntary contracting individuals can further organise solutions to the problem of scarcity. Individuals in local communities (before the state education system) contracted together to ensure provision of local schools. This can be seen as an organisational innovation that permitted more effective use of a local teacher's time, a scarce resource.

Trade is a process in which, through voluntary contracting, scarce resources flow to their most highly valued uses. In a situation where someone values a resource more highly than its current owner, a transfer of ownership is likely to be possible, with the purchaser being able to compensate the current owner out of the additional value he or she places on it. Thus through exchange, social welfare can be improved. Even the least technologically advanced societies practice barter, a form of exchange. The feature of modern exchange economies however is that they have developed a sophisticated monetary system (another institution) that facilitates exchange and avoids the problems in barter where both parties in an exchange have to have a commodity the other wants. Through voluntary contracts, either based on barter or by through money, ownership titles to resources are transferred, ensuring that resources flow towards those who value them the most.

Voluntary exchange governed by contracts and markets is thus a powerful process that allows interdependencies between individuals to be reconciled, facilitates organisational solutions to the problem of scarcity and enables scarce resources to flow to their most 
highly valued uses. In the context of simple transactions or exchanges, market contracting has many beneficial features.

The general arguments for the use of markets or private contracting as potential means of solving economic and social problems tend to focus on three main features of markets - first how markets enable efficient use to be made of information, second how markets, through the price mechanism, co-ordinate individual actions and resolve interdependencies, third how market competition puts in place a selection mechanism that over time tends to guide resources to those users and uses that maximise the value of production secured from the resources, as measured by consumers' willingness to pay. Markets at their best resolve conflicts impersonally and ensure that over the longer term less efficient producers are penalised and the more efficient rewarded. In the following discussion we consider each of the above points in more detail.

As institutions for consummating exchange, the role of markets in ensuring efficient use of information becomes apparent when it is realised that the acquisition of information has costs, and in many circumstances is difficult to transfer from one person to another. In such circumstances it is better if those with ready access to information, or those in possession of relevant specialised information attempt to find their own solutions, rather than risk ill informed interventions by third parties. Various organisational forms have evolved which allow specialisation in the production of information. These include such things as rating agencies, brokers of various sorts, research departments within firms, private educational organisations, and labour exchanges.

The notion that the price mechanism is an efficient means of co-ordinating individuals' action is in many ways also based on informational considerations. A price system can operate in a low cost manner to transmit to individuals wishing to claim the use of scarce resources the competing claims upon its use or the returns the resources can earn in alternative uses, and also the costs of their production in one simple signal. In a similar way to traffic lights, the major virtue of the price mechanism is its simplicity in both signalling information and co-ordinating behaviour.

Substantial empirical work indicates that prices do reflect and convey information about the extent of competing claims and costs of production to market participants. On the basis of prices individuals are then able to make production and consumption decisions in a way that incorporates wider social claims on resources. Efficient markets force individuals to make choices about the priorities they have, reconcile their demands with those of others and further provide incentives for individuals to conserve the use of resources wisely. All of these are socially desirable outcomes.

Significant resistance to the use of private markets is frequently based on the view that individuals searching for private gain will be unconstrained resulting in undesirable 
consequences such as exploitation, unfair trading and monopoly practices. Such market practices however are often disciplined by the market itself through competition. ${ }^{8}$ If through exploitation or unfair trading an individual or firm can earn a return in a particular activity that is above that earned elsewhere then there will exist incentives for others to enter the market and compete, thereby undermining the longer term survival prospects of such practices. Thus economic rents and privileges tend to be transient in the context of competitive processes, and are likely to develop and persist in the context of arrangements that inhibit such processes.

Decentralised markets based on competition also have many virtuous dynamic properties that make them preferable in many circumstances to protected markets or centralised control. More important than the short run competition based on price, described in the last paragraph, is the competition that imposes a selection process on different methods of organising production and distribution, and the same time provides incentives to discover new opportunities, new ways of doing things, new products and services. Competition creates an evolutionary process that tends to ensure that private ordering through markets is subject to evolution on all fronts over time, while also providing a check against abuse of power and privilege. Competition and markets can thus be seen as organisational arrangements that economically allow individuals to undertake mutually beneficial transactions while aligning the interests of the individual with those of a society.

\section{B Limits to Markets}

Private contracting nevertheless clearly faces limitations. The major sources of problems with private contracting are uncertainty, information problems and opportunism which were discussed in the earlier section. In the context of uncertainty individuals will face problems contracting about future events. For example a contract for the delivery of goods is complicated if the price of the goods may change according to movements in foreign exchange rates. Information costs also raise the costs of contracting. In particular individuals face costs searching out and evaluating potential contracting partners. An unemployed resident of Whangarei attempting to search for a job in Auckland or Wellington clearly faces considerable information problems. Finally, if individuals are opportunistic or incentives are not well aligned then people face costs contracting with each other. For example if one pays for goods in advance of delivery one faces the risk that the supplier will either not deliver or deliver poorly.

It is clear nevertheless that these problems are unlikely to be uniformly present in all exchange transactions. Voluntary contracting is thus likely to be efficient in the context of

8 For a discussion of such "unfair" contractual terms see B Klein "The Transaction Cost Determinants of 'Unfair' Contractual Arrangements" (1980) 70 American Economic Review 356. 
simple exchange relations such as those involved in auction markets, where there are many buyers and sellers and information is easily obtained. Capital markets exhibit these features. Even less perfect markets can nevertheless work well. Consider the new car market. Information can be relatively readily obtained by viewing the cars on sale or by testing them, and one can compare prices for different makes and models by simply walking around the market.

Problems will arise with voluntary contracting however when there are difficulties in measuring the quality of the goods being sold. ${ }^{9}$ Measurement problems result from the existence of information costs and bounded rationality. They arise in goods markets where the goods are complex, but more particularly in the context of sales of services, especially expert services provided by professionals such as doctors, lawyers, or accountants.

Problems also arise where the parties to the contract are engaged in a long term relationship supported by investments specifically tailored to the trading relation and reliant upon its continuity (that is, transaction specific assets). ${ }^{10}$ An example of such a situation includes that of a manufacturer who requires a steady supply of a unique piece of equipment not used by anyone else. In these circumstances the supplier may have to change his/her production processes to meet the specialised demand and be unable at low cost to turn to the production of alternative goods. In these situations there are a small number of buyers and sellers and bargaining will be complicated by the existence of information costs, bounded rationality and opportunism. The parties for instance will need to safeguard their relation against uncertain events. The absence of large numbers of alternative buyers or sellers with a coincidence of needs further means there is greater potential for haggling over the terms of trade, and for opportunistic behaviour.

Such behaviour however absorbs resources. Consequently private individuals seek to anticipate such occurrences by crafting safeguards in their contracts, or by seeking out alternative organisational forms that minimise problems. Examples of such private endeavours to minimise the probleme facing social and economic organisation are discussed below. The main examples are complex contracting, the firm, and the club or voluntary association.

9 For a discussion of the problems information and measurement costs create for the operation of markets see G A Akerlof "The Market for Lemons: Quantity Uncertainty and the Market Mechanism" (1970) 84 Quarterly Journal of Economics 488; and Y Barzel "Transaction Costs: Are They Just Costs?" (1985) 141 Journal of Institutional and Theoretical Economics 4.

10 For an analysis of contracting problems in the context of specific assets see Williamson (1985) above $\mathbf{n} 6$ and Alchian and S Woodward "Reflections on The Theory of The Firm" (1987) 143 Journal of Institutional and Theoretical Economics 110. 


\section{Complex Contracting}

Frequently when difficulties arise with private contracting, individuals develop organisational arrangements or practices which seek to minimise these problems. In more complex settings, or non-auction settings, non-standard or complex contracting emerges. Examples of non-standard contracting practices include entry fees, marketing restrictions and some types of franchising. These practices often appear unfair at first glance and suspiciously like monopolistic restrictions. However, they may be necessary in order to reduce uncertainty or scope for opportunism between the supplier and consumer, thereby making it economic for one party to invest in a specialised technique. Seen in this light such practices can be efficient. Frequently such non-standard or complex arrangements reduce the capacity of parties to a contract to renege or change the terms of an agreement. These restrictions can also be understood as efficiency enhancing particularly when there are the measurement problems or a small numbers bargaining situation pointed to earlier. In such cases the problems created for contractual partners by opportunism, are likely to be severe. For instance if the quality of a good or service is hard to measure then it will be easier for one party to cheat another. ${ }^{11}$

Reliance on a third party may be resorted to in order to deal with contracting difficulties. This is likely to take the form of privately arranged arbitration procedures that are more sensitive to the needs of the parties than the use of common law courts constrained as they are to apply general rules with little ongoing knowledge of the facts.

Perhaps the most frequent method besides arbitration relied upon by private parties to limit opportunism is the creation of what may be called credible commitments. ${ }^{12}$ Individual contractors may deliberately agree to commit themselves at the outset. Such commitments may serve to tie their own hands at a later date from behaving opportunistically. The arrangements likely to emerge here are similar to the mutual creation of hostages. Examples include bonds required by landlords of tenants and vested pension funds offered by employers. These types of contractual arrangements can be understood as attempts by landlords to protect themselves against opportunistic tenants, and attempts by employers to protect investments they may make in the training of workers. Sometimes however these arrangements may appear unfair and explanations are advanced that suggest that one party is using market power to extract unfair terms. One needs to be careful however to examine the detail and background to the creation of these apparently unfair terms. ${ }^{13}$ They may

11 See Williamson (1985) above $\mathrm{n} 6$.

12 For a discussion of credible commitments see Williamson (1985) above n 6.

13 See B Klein (1980) above $\mathbf{n} 8$ for a discussion of this point. 
often be better understood as attempts to safeguard integrity in a long-term relational contract.

In addition, problems associated with uncertainty frequently give rise to complex contracting. Individuals attempt to manage uncertainty. They take out insurance contracts, they buy on futures markets, they employ specialists either full-time or on retainers, they maintain inventories or they may merely self-insure through personal savings. Clearly attempts to anticipate all future events are costly. Examples of 70 page commercial contracts are not infrequent. In designing these contracting safeguards however individuals will weigh costs against benefits, and design contractual arrangements that best suit their needs over time.

To be sure, complex contracting restrictions that are observed may simultaneously serve the efficiency purposes outlined above or other antisocial (for example monopolistic) purposes. Here as elsewhere, where trade-offs are posed they need to be evaluated and the virtues of private arrangements not underestimated.

\section{The Firm}

The firm can similarly be interpreted as an organisational innovation that substitutes internal organisation of production for contracting across markets by autonomous agents, in order to minimise the costs of contracting. ${ }^{14}$ When a firm vertically integrates (or buys a supplier of services), it may be attempting an organisational innovation that reduces the costs of contracting. In these circumstances internal organisation may be more efficient than discrete market or complex contracting. Substituting administrative control for market relations may enable the pooling of information, improvements in communication and other reductions in bounded rationality, greater monitoring and control of opportunistic behaviour, co-ordination of production interdependencies and speedier resolution of contracting disputes. There may be gains both in adaptability and from improving integrity in exchange, by organising production within a firm. This is particularly likely in two cases. First when the parties are committed to a long term contracting relationship through the development of assets which are specific to their relationship and which have little value in alternative uses, and second when there are serious problems measuring the quality of a good or service provided, as in cases of team production.

The capitalist firm when viewed as an organisational innovation may be seen as socially beneficial in the way it may ensure the efficient production of goods and services for a market using team work. With team work it may be difficult to measure the contribution of each team member and shirking (opportunism) may become a serious

14 This view was first advanced by R H Coase "The Nature of the Firm" (1937) 4 Economica 368. 
problem. ${ }^{15}$ As the residual income or profits left after production is claimed by the owner of a capitalist firm he or she has an incentive to monitor production and minimise production costs in order to maximise his or her income. ${ }^{16}$ Over time this operates to the benefit of the consumer as, through the increases in productivity it enables, and through competition, prices may be expected to fall. Moreover the existence of the capitalist as a residual risk taker or the party accepting the costs of uncertainty is also relevant to the assessment of the firm as an effective organisational innovation. Fundamentally the capitalist firm may enable specialisation in the management of risk or uncertainty.

Within the community there is often a general expression of hostility towards large dominant firms. This view is based on a suspicion that the expansion of a firm into different activities has monopoly purposes. Recent research however suggests that attempts to expand or take control of different levels of production and distribution may be based on the efficient adaptations of private individuals to eliminate the problems experienced with market contracting outlined above. ${ }^{17}$

It is true nevertheless that firms can behave opportunistically and exploit a monopoly advantage. The key question is, are there checks on this behaviour. In fact the number of firms operating in a market, or dominance, may not be the critical factors, rather the ease with which new firms can enter the market, or the threat of competition to, or contestability of, the firm's activities may be the relevant element. If there are low barriers to entry then checks upon monopoly behaviour will exist. Frequently, where they exist, barriers to entry are in fact created by regulation. An alternative way of looking at the problem is to examine the costs of exit from a contracting relationship that a purchaser or supplier has. If these are low then there are checks on behaviour. Firms further need to maintain their reputation. The potential loss of reputation therefore acts as a check. Monitoring by consumers, by potential rivals, and by Government (involving the threat of regulation) are all likely to act as a check on behaviour. Moreover co-operative organisations or alternatives to the capitalist firm may be expected to survive over time if they are more productive, so long as the legal framework is neutral. Basically one needs to be sensitive to the incentives of private individuals to eliminate practices which are exploitative and take precautions against them in mutually beneficial ways.

15 On this point see A Alchian amd H Demsetz "Production, Information Costs, and Economic Organisation" (1972) 62 American Economic Review 777.

16 See E F Fama and M C Jensen "Separation of Ownership and Control" (1983) 26 Journal of Law and Economics 301-326, and Fama \& Jensen "Agency Problems and Residual Claims" (1983b) 26 Journal of Law and Economics 327.

17 For a transaction cost explanation for multiproduct firms see D J Teece "Towards an Economic Theory of the Multiproduct Firm" (1982) 3 Journal of Economic Behaviour and Organisation 39. 
The major problem that large internal organisations create however is a weakening of incentives to perform. When transactions do not involve measurement problems, or specific assets, markets can be more effective. Within a large firm the checks on shirking can be comparatively low and the costs of monitoring and effectively encouraging efficient production may be weaker than when transactions are organised across markets. Further, bureaucratic rules and attitudes may hinder dynamic behaviour. These disabilities suggest that individuals may rely more on market oriented solutions to contracting problems, that may retain a higher level of competitive checks and incentives, such as those described earlier when we discussed complex contracting.

The above suggests that the firm can be understood more broadly as an organisational innovation or as a nexus of contracts between resource owners. Owners of labour, capital and land join together to provide goods or services to a market in an organisational unit that enables greater gains for each than independent or autonomous contracting.

\section{E Voluntary Associations}

Other coalitions of private individuals or organisational forms can be identified which seek to pursue the mutual interests of members other than firms. These can be described as voluntary associations and include among other institutions clubs, churches, and unions. These coalitions can be understood as the creation of individuals contracting with each other to deliver a good or service of benefit to themselves as a group. ${ }^{18}$ The services they provide may benefit their members exclusively, or benefit the wider community (for example a club house versus a public park). While the problem of poor incentives or opportunism may arise in this context as well and limit the extent to which individuals may be able to achieve collective goals the problems should not be over-emphasised. Indeed in one view non-profits are an institutional response that may, for example, facilitate altruism by donors to charities. In a related view non profits are seen to be a means of limiting opportunism by service providers particularly in situations where consumers are poorly informed relative to sellers. Consumers in such circumstances may prefer to rely on nonprofits, to the extent they may be assumed more reliable or trustworthy, and less likely to exploit their informational advantage for short term profit. Information problems in judging services of nursing homes, day care for children, blood banks, medical research,

18 Two seminal articles on voluntary associations are Buchanan "An Economic Theory of Clubs" (1965) Economica 32, 1, and Olson The Logic of Collective Action (Harvard University Press, Cambridge, 1965). For a review of the literature on clubs see R C Cornes and T Sandler The Theory of Externalities, Public Goods and Club Goods (Cambridge University Press, Cambridge, 1986). For recent work analysing the role and economics of non-profits see B A Weisbrod The Non-Profit Economy (Harvard University Press, 1988); and Susan Rose Ackerman (ed) The Non-profit Sector: Economic Theory and Public Policy (Oxford University Press, 1988). 
environmental protection, and charities for the needy for example may explain the dominance in these areas of non-profits. ${ }^{19}$

The main situation however where opportunism is thought to undermine the effectiveness of voluntary associations arises in the case of public goods. A pure public good can be defined in theory as a good that can be used by additional consumers at no extra cost, and for which it is not possible to exclude people from consumption (for example a radio broadcast in the absence of coding). In the case of a pure public good poor incentives or opportunism may lead some individuals to 'free ride' on the collective benefits achieved by others from which they cannot be excluded. It is suggested that such opportunistic behaviour may lead to the instability of clubs or associations which voluntarily attempt to deliver pure public goods. This free rider problem can however be over-emphasised. Generally, the stringency of the conditions for a good to be truly public, needs to be recognised. ${ }^{20}$ Few goods are likely to involve zero marginal cost for use across any significant range. Further, if the individual does not participate in clubs or associations that may seek to provide public goods then the quantity or quality of public goods that will exist will probably be reduced, hence a cost is incurred by non-participants and their 'ride' is not free but rather cheap. In the extreme in fact the collective good or service may not be provided at all. Moreover whether a good is truly public or not, depends on whether people can be excluded from its use. This may depend as much on the institution used to produce it as on the nature of the good. For instance this is illustrated by decisions about whether or not to charge admission to amusement parks. Similarly, cable television has reduced the 'public' nature of television broadcasting.

The benefits of voluntary attempts to deliver goods are that they may ensure the goods delivered are better tailored to the needs of the benefiting population. The decisions made on what goods should be provided are made by club or association members, and furthermore if a member disagrees with the ultimate decision of the group they can freely leave the group and seek another one that better meets their needs. In this way voluntary coalitions may be better able to satisfy demands for goods frequently seen to be of a public nature than centrally determined solutions.

Two limitations of such solutions however are frequently suggested. First it may be thought that in a heterogeneous society people joining clubs or voluntary associations to provide services may lead to the segregation of peoples with consequent losses in social cohesion. Cohesiveness however is not valued above all else and it may at times conflict with another value, namely diversity. In fact, true social cohesion may only be attainable

19 For this view see Weisbrod (1988).

20 For a sceptical view on the evidence on the existence of public goods see Coase "The Lighthouse in Economics" (1974) 17 Journal of Law and Economics 357-376. 
through greater tolerance of diversity. Moreover a voluntary association needs to be recognised as a key institution that serves social cohesion by bringing individuals together in collective endeavour.

Second it may be suggested that with a mobile society such private solutions to the provision of certain goods may be undermined, particularly with regard to collective goods that involve large set up costs. This suggests that reliance on voluntary associations for provision of public services may hinder mobility. Mobility, however, has costs, and where it is highly valued one might expect individuals to find means to facilitate it. Thus there may be inherent tendencies towards appropriate systems of networking where cohesion and mobility are valued by individuals.

\section{F Conclusion}

The above discussion attempts to indicate the useful role of private arrangements as means for resolving conflicts of interests and achieving collective goals even in the context of serious organisational difficulties. It attempts to point out common fallacies or misconceptions about the poor effectiveness of private arrangements. At the same time it emphasises that private arrangements have weaknesses or face limits. In particular private arrangements are likely to face problems arising from information costs, bounded rationality, opportunism and uncertainty. Our discussion in the section which follows goes on to show that these problems are nevertheless common sources of failure of centralised solutions. A relative assessment of the abilities of private versus centralised attempts at solutions to social problems is therefore warranted.

\section{The Role and Limits of the State}

\section{A The Role of the Law and the State}

In the section on the constraints to achievement of social goals we identified five problems which must be faced by individuals in organising their relations and activities. These were the problems of scarcity, interdependence, uncertainty (or bounded rationality), information costs, and opportunism (or incenive problems).

The problems of scarcity and interdependence require solutions by which different individuals' competing claims can be reconciled so that resources are not wasted but are employed in their most socially valued use. The outcome will be the existence of rights either in fact or in law. These rights will express relationships between individuals in respect of the use of scarce resources, or actions which are a source of interdependence.

There are three basic elements to property rights over scarce resources. First is the right to use the resource and to retain income accruing from its use. Second is the right to change the nature of a resource (for example to put a factory on farm land). Third is the right to 
transfer these rights. The crucial feature of all of these rights is the extent to which they are exclusive or good against all comers, or against the competing claims of others.

Exclusivity in property rights creates incentives for individuals to use resources efficiently. To the extent that an individual or a group has an exclusive right to use and transfer a resource, they will face incentives to use the resource well and to develop it. With an exclusive right over land for instance one knows that if one fertilises the land, one will be able to capture the benefits of its improved productivity, without risk of this greater productivity being 'stolen' perhaps by a neighbouring farmer's grazing herd. This improves incentives to carefully husband and improve the land. Further with exclusive rights one can sell or transfer the rights to others who may value them more highly. It can be claimed then that, depending on the way they are specified, exclusive property rights can improve incentives and enable more effective use and allocation of scarce resources, in comparison to a situation where no one can claim exclusive title.

The fact that rights - de facto or de jure - express relationships between people however implies the need for them to be mutually recognised for them to be observed. Rights can be backed coercively, by less formal sanctions involving custom, social mores, or by contract.

In a process of voluntary contracting, rights or relations between individuals, both in respect of scarce resources and each other, are continually being defined, allocated, redefined and reallocated. The definition of rights through voluntary exchange is a dynamic process that among other things responds to changes in technology, preferences, income, relative prices, population and the need to minimise the general problems indicated above. The process further involves decentralised decision making which enables quick adaptations to new information and incentives.

In a process of private regulation based on voluntary exchange, individuals seek to enforce and mutually recognise each others exclusive rights to use and transfer scarce resources in an interdependent world. Such rights based on exchange are characterised by a remarkable degree of durability or observance. The glue which makes a contract stick is the mutual advantage that underlies it. The creation of exclusive rights over resources through a contract is further likely to be socially beneficial as exclusive rights enhance the incentives for individuals to use resources efficiently.

The above analysis raises a fundamental question about the role of the law. Given contracting is permitted will the law have consequences, and more fundamentally is it needed? The above suggests first of all that if legal rules allocating rights exist, but leave the 
legal rights tradeable ${ }^{21}$ and contracting costs are zero, it does not matter for efficiency what the law actually says. In such conditions private parties will change any rule with adverse consequences for efficiency by changing the rights created by the rule by agreement in order to exploit the gains from exchange inherent in any departure from efficient outcomes. Coase summed up this point in the so called Coase theorem by saying while: ${ }^{22}$

the delimitation of rights is an essential prelude to market transactions ... the ultimate result (which maximises the value of production) is independent of the legal decision.

Subsequently Cheung has taken this analysis one step further and argued that, even in a world of scarcity and interdependence, if transaction costs are zero: ${ }^{23}$

the assumption of private property rights can be dropped without in the least negating the Coase Theorem.

This is a view which Coase commented was "no doubt right". ${ }^{24}$ This suggests that even if there is no initial allocation of rights by legal rules efficiency will result. ${ }^{25}$

One can identify at least six problems however with purely private regulation and formation of rights. These problems are:

(a) Rights formed on the basis of contract alone are not likely to be respected by all individuals, at best they may only be respected by those who are parties to the contract. The problems of bounded rationality, information costs and opportunism can be understood to lead to situations where no contract emerges to govern interdependencies between people, and for uncontracted for effects to therefore emerge. This limited coverage, and therefore exclusivity of contractually based rights undermines incentives to use resources efficiently and may in fact undermine the operation of markets.

21 Whenever legal rules may be waived by agreement, or can be amended by private parties, then the legal rights they establish can be termed "tradeable" or alienable. Thus if, for example, a legal rule permits workers to sell their right to associate in employment, or their right to expect unanimity in unions, or permits the firm to sell their right to be free of intimidation, then these rights are tradeable, much like commodities.

22 Coase "The Federal Communications Commission" (1959) 2 Journal of Law and Economics, 1, 25.

23 Cheung, Will China Go "Capitalist"? Hobart Paper 94 (London Institute of Economic Affairs, London, 1986) 37.

24 Coase The Firm, The Market and The Law (University of Chicago Press, Chicago, 1988) 15.

25 For empirical work on the private formation of property rights, without the state, in a positive transaction cost world, see J Umbeck "Might Makes Rights: A Theory of The Formation and Initial Distribution of Property Rights" (1981) 20 Economic Inquiry 38; and T L Anderson and P J Hill "The Evolution of Property Rights; A Study of the American West" (1975) 18 Journal of Law and Economics, 163. 
(b) Attempts by individuals to address this or create absolute exclusivity of rights may lead them into conflict, either as individuals or groups. ${ }^{26}$ Depending on the cooperative tendencies of people, unless there is a more powerful force, or an organisation such as the state that can effectively monopolise coercive powers, the law of the jungle may prevail. This tendency may lead to a situation where more resources are wasted on enforcing exclusivity, than would be required if there was an organisation such as the state that enforced rights on a generally accepted basis. ${ }^{27}$

(c) Those rights formed on the basis of exchange may moreover not even be respected even by the parties to the exchange themselves. Given the condition of opportunism highlighted above, it is going to be difficult to design self-enforcing agreements. ${ }^{28}$ Enforcement of contracts by a third party in possession of coercive powers may then enhance the range and feasibility of exchange or contracts between individuals and contribute to wealth creation through exchange.

(d) Fourth the costs of contracting facing individuals may mean that status quo rights definitions that are not socially desirable, continue in existence. Essentially the contracting costs facing private individuals attempting to change the current definition of rights may preclude an appropriate or socially desirable adjustment. Consider a status quo rights definition that effectively gave people the right to burn down factories. Because of the high costs facing factory owners in identifying and contracting with potential factory burners, such a rights definition is likely to persist and give rise to more burnt factories, lower employment and lower consumer welfare, when compared with an alternative rights definition that prohibited arson..$^{29}$

(e) Fifth, it is usually felt that a purely private process of rights formation may not be ethically desirable. It may be seen to be potentially inequitable and potentially lead to a de facto situation where might defines rights.

26 See R Cooter "The Cost of Coase" (1982) 11 Journal of Legal Studies, 1 for a discussion of "Hobbesian" versus "Coasean" bargaining assumptions that may characterise differences in view on this. See J Umbeck "Might Makes Rights: A Theory of The Formation and Initial Distribution of Property Rights" (1981) 20 Economic Inquiry 38 for a discussion of actual property rights formation in the absence of the law during the Californian Gold rush.

27 See G S Becker "Crime and Punishment: An Economic Approach" (1968) 76 Journal of Political Economy 169 and G S Becker and G J Stigler "Law Enforcement, Malfeasance and Compensation of Enforcers" (1974) 3 Journal of Legal Studies 1 for formal economic models of an analysis of the role of criminal law and its enforcement.

28 On self-enforcing agreements see Telser "A theory of self-enforcing agreements" (1981) 53 Journal of Business 27.

29 See Demsetz (1982) 72 "Barriers to Entry The American Economic Review" 47, 59 for a discussion of this point. 
(f) Finally it is frequently felt that private arrangements may provide insufficient safeguards for the dignity of people, leading to alienation with consequent losses in overall welfare.

The basic conditions of scarcity, interdependence and the need to reconcile competing claims through the definition of rights creates a need then for an institution that has a monopoly on coercive powers and adjudicates on the rights of individuals where necessary. This will involve both the allocation of initial rights where no contract exists, and the enforcement of rights formed through agreement or exchange. This is perhaps the fundamental explanation for the existence of government and law. It is the ultimate safeguard to ensure that individuals in pursuit of their own self-interest reconcile their competing claims through peaceful means, and undertake productive investments in property, rather than waste resources, time and effort in violent and aggressive behaviour. By defining initial rights and enforcing contracts it may also facilitate exchange, expand the range of feasible contracts, and expand trade. In performing this role of enforcer and specifier of rights the Government is clearly not performing a simply technical function, but rather is expected to have regard to ethical criteria.

So far then we have elaborated how the role of the state as a monopolist of coercive powers, that ultimately specifies and enforces property relations or rights, is central to the effective operation of voluntary arrangements including markets. In such a context it may be inappropriate to speak of government intervention in markets. Government involvement in enforcing property and contracting rights may be necessary in order for markets to work. If governments may be the basis of markets, to speak of them interfering in markets seems slightly misplaced. Government involvement in markets is pervasive and therefore the notion of a market totally free of government intervention may be meaningless. Indeed even if a government did not exist one can suggest there would be a tendency for one to form out of the demand by individuals for an organisation to enforce exclusive rights.

All the same the above analysis also highlights that as a prelude to any government intervention it is important not to take the above conditions undermining private arrangements as everywhere and always present. Rather detailed analysis of the existence, nature and source of a problem in private arrangements needing to be addressed is needed.

The relevant questions then do not include whether or not in general Government should exist or intervene but under what conditions and how. The question of how it intervenes is also critical in this regard, as by its interventions in private arrangements the Government may make matters worse. Thus in the same way as private arrangements may fail, so too may government imposed ones. A detailed comparative assessment of consequences of actual alternative options or choices, including leaving things as they are, is therefore what is needed. 
In what follows we shall proceed to a discussion of the nature and consequences of the various means the State has at its disposal for defining allocating and enforcing rights and thereby affecting social outcomes. ${ }^{30}$

\section{$B$ The Courts and the Common Law}

One option available is to leave the resolution of what legal rights should be created, for whom and how, to court decision-making. Indeed the courts tend to reserve the right to have the final say about disputes involving legal rights - subject to appeals to higher courts and legislative intervention - leaving this option always open to the parties to a dispute.

Three main choices for enforcing legal decisions allocating rights are identifiable. ${ }^{31}$ These are an inalienability rule under which a right (eg freedom from slavery) is made inalienable, second a so called property rule where a right is enforced by injunction (but the parties are able to bargain to transfer the right), and a liability rule where the right is enforced by compensatory damages (or where in essence the court determines the price for the transfer of the right which may have occurred eg in a car accident). The courts moreover ultimately have the sanction of coercively appropriating property or imprisoning individuals who fail to observe their decisions and enforcement awards.

In comparison to relying on private ordering then what problems will judges face in settling disputes? The role of bounded rationality and information problems in court decision making is critical in this regard. Judges are human, they have difficulty forming judgements. Even if they are assumed good at it they also however face information costs. If all relevant information were public, or available to all parties and the court at zero cost, then a court may be able to make a decision that approximates a value maximising exchange. Where however there is information held privately by the parties, or where it is costly to access information, then such an outcome is less likely. If information is held privately by the parties then two situations are worth distinguishing. First a situation where information is held privately by the parties, but in common. Thus both know the relevant facts, but the court does not and faces costs accessing it. The second is where the information is held privately by the parties but asymmetrically. Thus one party holds information that the court and the other party do not

In either situation of private information it will be difficult for a court to minimise transaction costs. Where transaction costs include both the direct costs of ensuring value

30 For general introductory texts on much of what is discussed in what follows see R Posner The Economic Analysis of Law (3 ed, Little Brown \& Co, Boston, 1986) and R Cooter and R Ulen Law and Economics (Scott Foresman \& Co, Illinois, 1988); and D C Mueller Public Choice II (Cambridge University Press, Cambridge, 1989).

31 Calabresi \& Melamed, "Property Rules, Liability Rules and Inalienability: One view from the Cathedral" (1972) 85 Harvard L Rev 1089. 
maximising exchanges of rights occur, and the costs of exchanges that may be forgone because they are too costly to consummate. The courts' capacity to perform well as an institution of dispute resolution in the instant case will depend on the substantive legal rules providing the basis of court intervention (including those of contract and tort ${ }^{32}$ ), the remedies adopted for enforcing rights, and the legal procedures applying (eg evidence).

Whether poor legal decisions, which are no doubt then likely to emerge, then have consequences for the efficiency of the relations that emerge as between the parties to the case, depends on the parties' ability to bargain subsequently about the outcome to rearrange it, or appeal the decision. It would thus appear likely that poor decisions in a case will persist and have adverse effects subsequently, to the extent information problems between the parties are likely to have caused the original decision to take the dispute to court, rather than settle privately.

One needs to add to this potential risk, the likely wider impact of legal decisions on third parties, given the effect of legal precedent or the doctrine of stare decisis. The question then becomes whether judges will be able to settle disputes that are generally efficient, not only for the parties but for third parties as well. Will the basis of judgments in a particular case for example be accurately enough stated so as to clearly signal the limits of its application, and will those limits be appropriately set.

Clearly the costs of a court accurately assessing potential third party effects will again be undermined by the information problems involved in such assessments. At the same time however those involved in any litigation will have incentives to identify potential adverse third party effects, basing their arguments on the public policy doctrines for legal decisions. This may then provide a process in the particular cases for the limits of the decision to be elaborated clearly and appropriately. This process however will be costly and imperfect resulting in the likelihood of adverse third party effects.

The question then is whether third parties will be able to avoid the impact of such bad decisions or eliminate them over time. Again this will depend on the costs of them agreeing with others on the meaning and applicability of a particular decision and then bargaining about its impact to re-arrange its possibly adverse consequences. It has been suggested however that the process of litigation may provide a mechanism akin to natural selection whereby inefficient legal rules are eliminated in the long run. ${ }^{33}$ This is based on an

32 See Cooter "Unity in Tort Contract and Property: The Model of Precaution" (1985) 73 Californian Law Review 1.

33 For seminal articles on this see Rubin, Why is the Common Law Efficient?" (1977) 6 Journal of Legal Studies 51; and G L Priest "The Common Law Process and the Selection of Efficient Rules" (1977) 6 Journal of Legal Studies 65. See also G L Priest "Selective Characteristics of Litigation", (1980) 9 Journal of Legal Studies 399; G L Priest and B Klein "The Selection of Dispute for Litigation" (1984) 23 Journal of Legal Studies1; R Cooter and L Kornhauser "Can Litigation 
assumption that inefficient legal rules are more likely to be overturned than efficient ones, because overturning them increases wealth, instead of potentially reducing it, or merely redistributing it.

The efficient outcome could emerge in the long term even if judges do not consciously favour efficiency; and even if they suffer bounded rationality. It would suffice if they do not on average systematically favour either efficient or inefficient outcomes. If one assumes a neutral judiciary, two effects may then generate a bias in the common law process towards efficiency. First it is possible to argue that rational self-interested litigants will tend to litigate inefficient decisions more frequently than efficient ones. This is true, with given costs of litigation, to the extent the expected gains from litigating inefficient rules will be higher than efficient ones (ie by definition, overturning inefficient rules increases the potential value to be distributed between the parties). Second however it is also possible to argue not only that inefficient rules will be more frequently litigated but that more will be spent on the litigation of inefficient rules than efficient ones. This potentially implies better prepared cases, and therefore better decisions in the particular case.

The above suggests a bias towards efficiency in the common law. This outcome however depends fundamentally on the distribution of the costs and benefits of legal rules and therefore the balance of incentives amongst potential litigants. If for example the benefits of an inefficient rule are concentrated on a small number of people and the costs are dispersed across a large number then opportunism (in the form of rent seeking behaviours) by those who stand to benefit most may lead to the litigation processes being biased in favour of the inefficient rule. Conversely if the benefits of efficient rules are dispersed, then because the costs of litigating are concentrated, opportunism (this time in the form of free riding behaviours by those who may benefit from a change to the rule but who wish to avoid the costs of changing it) may lead to sub-optimal rates of litigation in favour of more efficient rules. Basically no potential beneficiary of litigation may be willing to come forward to litigate for a more efficient rule.

The above suggests that the efficiency of the common law will depend on a number of factors. It may not be a proposition which is generally sustainable in all circumstances. Thus in some situations it may be better to leave matters to private ordering, or look at other
methods of social organisation.

Improve the Law Without the Help of Judges" (1980) 19 Journal of Legal Studies 139; S Shavell "Suit Settlement and Trial: A Theoretical Analysis Under Alternative Methods for the Allocation of Legal Costs" (1982) 11 Journal of Legal Studies 55; and S Shavell "The Social versus the Private Incentive to Bring Suit in a Costly Legal System" (1982) 11 Journal of Legal Studies 333. 


\section{The Analysis of Representative Government}

The other main option, or form of state intervention, chosen in most western economies for overcoming the problems of social organisation is representative democracy. So far we have seen that there is clearly scope for poor outcomes to emerge which a representative government might seek to address. Since the Second World War moreover the size of representative governments and the nature of their involvement in the economy has grown and changed rapidly. In this section we assess:

- the nature of this involvement in terms of the interventions a representative government has at its disposal and their likely effects; and

- the general sources of potential failures in such interventions

\section{The Instruments of Government Policy and their Effects}

Taxes, subsidies, regulations and government ownership are all examples of instruments by which a state specifies the rights of individuals. Taxes determine an individual's right to income accruing from the use of a particular resource. Subsidies similarly affect this right, and since subsidies to one individual must be financed by taxes on other citizens (fiscal or inflationary), or by debt to be paid back by taxes on future citizens, subsidies define rights or relationships between people. Regulation here is taken to cover both Acts of Parliament and Orders in Council. They clearly are used to define rights. Government ownership similarly defines rights between individuals.

Typically the Government rarely acts through one instrument, but through mixes of them. For example when a government regulates it usually becomes the owner of a regulatory agency and spends money on it. Rather than speaking of government instruments or interventions it is perhaps more useful to speak of a policy framework or a government policy. In the following few pages however we briefly discuss the effects of the main policy instruments - namely expenditure, taxation, regulation and state ownership - separately. We further discuss the option of devolving decisions to local democratic control.

In each case the discussion focuses on the general nature of each instrument and the problems each engender, not on the question of what is the best policy to adopt in relation to particular problems such as public goods, or monopolies. It is not possible to answer such questions in a general way, rather one needs to approach each area on a case by case basis, wary of the problems likely to arise with government intervention, and thereby utilising a comparative systems approach.

The method used to examine the effect of a particular government instrument (such as taxes, subsidies, etc) is in terms of its effect on the constraints individuals face, and therefore the incentives they create, and their consequent effect on the behaviour of economic actors. 


\section{Taxation}

The efficiency effects of taxation arise through the way they change the incentives facing individuals and firms. Where general taxation (PAYE, GST) is used to support particular expenditures, and thereby support certain rights of some individuals (eg in access to education) in a general way, then the costs of raising the taxes need to be evaluated and minimised. General taxation used to finance such expenditure for example will create disincentives to work, save and invest, and encourage economically wasteful activities aimed at avoiding tax. ${ }^{34}$ These outcomes need to be evaluated and minimised both when taxation policies are considered and when evaluating the benefits from expenditure programmes.

The great majority of taxation is of a general form designed primarily to support general government expenditure policies as above. Taxation however can be more specifically targeted, or used as an instrument to deter particular actions (eg pollution), or protect the rights of others. In this case it is important to evaluate not only the effects of the taxation on the targeted behaviour but also, what is done with the revenue and the economic effects of the use made of the expenditure on incentives and behaviours of other agents.

\section{Expenditure}

The efficiency costs of expenditure can be direct or indirect. The direct efficiency costs of a subsidy arise through the way it alters incentives for individuals. Subsidies may discourage work, or encourage investment in areas where it would not otherwise have been undertaken. There will thus typically be a forgone activity or opportunity cost that needs to be incorporated into decision making that involves government expenditure. This will critically depend on the method used to deliver expenditure. Thus the terms on which government money is made available to individuals (eg beneficiaries), or the terms on which the Government's purchases of outputs from firms are negotiated or regulated, will critically affect incentives and outcomes.

Expenditure moreover needs to be financed. The indirect costs of expenditure will thus also depend on the way it is financed. These costs will have to borne by economic actors, and essentially illustrate the interdependent nature of the economy. The indirect efficiency costs of financing expenditure when taxation is used were discussed in the last subsection. Alternative financing mechanisms however include debt financing and the creation of money.

The indirect efficiency costs of debt financing relate to the effect that public sector borrowing has on the supply of capital and rate of savings in the economy. These are

34 For an analysis of the costs of raising taxes in New Zealand see W E Diewert and D A Lawrence The Marginal Costs of Taxation in New Zealand (Swan Consultants (Canberra) Pty Ltd, 1994). 
affected through various mechanisms but primarily through interest rates and expectations. Large public sector debt programmes put pressure on interest rates that adversely crowd out private sector activity. Debt financing will also place a burden on future generations and therefore have intergenerational equity effects. ${ }^{35}$

If expenditure is financed by creating money it will cause inflationary pressures involving efficiency and equity effects. If the inflationary effects of expanding money supply to finance expenditure are not anticipated by economic agents (eg built into interest rates) then it may create advantages for borrowers, and disadvantages for savers and lenders with potentially adverse effects for borrowing and saving decisions. The inflation created by this means of funding expenditure will also tend to increase the uncertainty facing firms making investment decisions. This is true to the extent they will have difficulty judging whether price rises are general or relate only to their own markets.

\section{Regulation}

Regulation ${ }^{36}$ by central government also can be used to define the rights and obligations of individuals. Provision then needs to be made for the rights and obligations to be administered or enforced, which may occur by administrative agencies and/or the courts. Regulations effectively impose a quasi-tax or cost on some, and confer a quasi-subsidy on others. They can then have adverse efficiency effects if they allocate rights poorly, or reduce exclusivity of property rights; if they prevent more effective private arrangements emerging by raising the costs of contracting, or create barriers to mutually beneficial trades where they are appropriate; and if they fail to provide for the successful administration or enforcement of rights. They can also potentially have equity effects if they serve to protect privilege, or prevent access to opportunities of some groups.

\section{State Ownership}

A further instrument for government policy involves the assumption of ownership rights over agencies or firms. This gives government residual property rights over the assets of the firm, and therefore rights to directly control decisions relating to the income, use and transfer of the assets. As indicated in the earlier section on private arrangements, ownership may be appropriate where there are significant costs to contracting between autonomous agents. An owner of a firm or organisation may typically have access to better

35 For an analysis of the fiscal burden that current New Zealand policies will impose on future generations see A J Auerbach, B Baker, L J Kotlikof and Walliser, "Generational Accounting in New Zealand: Is There Generational Balance" (1995) Paper presented to NZ Economist Association Conference, Lincoln University, August 1995. economic analysis of regulation see G J Stigler "The Economic Theory of Regulation" (1971) 2 Bell Journal of Economics and Management Science 3. 
information and achieve greater adaptability in securing supply. However while ownership can be beneficial it can also be costly. Fundamentally the incentives of managers and employees of organisations are difficult to align with the goals (of the owners) of the organisation. This arises because of the problem of opportunism. Individual members of organisations have a tendency to pursue their own goals, to shirk and to featherbed, and to pay insufficient care in the use of resources that are owned by "the organisation" or someone else. This category of problems with ownership can be classed as principal-agent problems.

Whereas firms engaged in competitive or contestable markets supplying goods to a consumer face checks on their behaviour and need to ultimately serve consumers as well as other firms can, a state owned enterprise even in a contestable market can have greater leeway. This results ultimately from the fact that the state as owner has a tendency to underwrite losses and a greater capacity to do so through its ability to tax. While some checks involved in the managerial market or the ability to hire and fire managers are present for both state and privately owned organisation, state owned organisations lack some of the controls present in most private firms and are frequently given conflicting objectives. ${ }^{37}$ Large private firms on the other hand are typically open corporations, with their shares being traded on the capital market. If managers in a company do not maximise the goals of owners the company's share price will tend to fall. The value of the capital assets, or cash flow of the firm in alternative uses will at some point eventually exceed the share price and a takeover bid is likely to follow. The first change a successful takeover company is likely to make is to restructure the organisation and fire existing managers. This capital market check then serves to keep managers of private firms from pursuing sub goals and provides a mechanism through which control and monitoring systems are improved. These checks do not exist in the state sector to the same extent.

Ownership therefore has costs and the point to be borne in mind is that frequently social objectives may be more efficiently achieved through subsidies or taxes, or regulation of privately owned companies or contracts with them, rather than through state ownership. In those areas where the state cannot adequately secure an objective without ownership or there are net gains to ownership, then the state needs to be concerned on an ongoing basis to review and improve its internal management control systems.

\section{Local Democratic Control}

Local democratic decision making is frequently proposed as a possible alternative means for resolving conflicting interests and achieving collective goals, while avoiding many of the problems of extensive central government involvement. When local

37 As a result not only is there a lack of incentives or rewards for monitoring, monitoring is more difficult or costly. 
democratically elected units result from private arrangements the relevant perspectives for assessing such outcomes are those discussed earlier in relation to voluntary associations. Devolution of decision making power by central government to locally elected bodies through a centrally determined legislative framework however is the focus of our attention here. Although in effect it represents a case where the various instruments described above are being used in unison, the devolution of decision control to a local democratic unit warrants its treatment as effectively a separate policy instrument of a unitary central state such as that which exists in New Zealand.

The main advantage offered for decentralising control to local bodies is the likelihood that better solutions will result if those making decisions are close to the problems being addressed. This is based on the notion that those who have the information should make the decisions. The existence of different jurisdictions offering different mixes of output, quality and cost then enables voters to vote with their feet, as well as through the ballot box to ensure accountability of decision making. ${ }^{38}$ This argument is used in support of all forms of decentralisation.

There are a number of reasons however for concern with the effectiveness of this particular institutional option. Fundamentally there is a need to be sensitive to the method by which decentralisation is achieved in these matters. ${ }^{39}$ In many cases the local electorate typically appears to exhibit weak interest in the prudent use of resources by elected managers. This is so, particularly, in cases where central government provides the bulk of resources which the local body administers. It is possible to suggest that so long as either or both the expenditure or control exercised by the local body is laid down from the centre the local electorate is likely to be relatively divorced from or disinterested in the management process. So long as the finance for expenditure is not raised locally by the local body, and so long as the source of the body's ultimate control does not lie with the body itself but with the centre, the local electorate is likely to exhibit less interest in holding the locally elected members to account. A kind of rational disinterest may be expected to prevail.

\section{The Limits to Representative Government}

We identified earlier the problems of scarcity, interdependence, bounded rationality, information costs and poor incentives which can undermine the effectiveness of private arrangements. Exactly the same problems that compound or undermine private arrangements, however, undermine attempts at finding central government solutions through the above instruments. Thus central government attempts to improve the outcomes of private

38 On voting with feet see C M Tiebout "A Pure Theory of Local Expenditures" (1956) 64 Journal of Political Economy 416.

39 For a discussion of the issue of allocating different functions to different jurisdictions see W E Oates Fiscal Federalism (Harcourt Brace, London, 1972). 
arrangements, or supplant private endeavours to solve the basic problems of scarcity and interdependence are similarly constrained by scarcity of resources, interdependencies, bounded rationality, information costs and incentive problems. In many ways, however, the problems may be more severe. Let us then turn to consider the problems facing central government decision-making.

The problem of scarcity may be exacerbated by central government. As we have just seen its policies may distort the incentives of individuals who are affected by the interventions. Thus as just outlined all government policy instruments tend to have adverse effects, and are not costless. Similarly the state's attempts to deal with interdependencies may in fact create worse outcomes. In part this reflects the basic fact of interdependency in the economy. As we have seen an intervention in one market may have adverse consequences elsewhere that are unforeseen.

To set the stage for analysing the sources of government failure in confronting these problems, we begin with a government based on direct democracy (no representative government). If we assume a world of direct voting on a single issue under simple majority rule, ${ }^{40}$ under these conditions it can be shown that the median voter's preferences will be decisive in determining the collective outcome. ${ }^{41}$ But there is nothing in the voting process to ensure the median voter's decision is the efficient one. ${ }^{42}$

The sources of inefficiencies arising from government are even more complex when we go to a system of representative democracy. Like private individuals, decisions makers in a representative government will face difficulties dealing with the problems of scarcity and interdependencies that underly problems of social organisation. The reason of course is

40 For a discussion of the costs of decision making under alternative collective decision rules to majority rule see J M Buchanan \& G Tullock The Calculus of Consent (University of Michigan Press, Ann Arbor, 1962).

41 For simplicity we are ignoring the problems of stability of majority rule outcomes. Majority rule can result in what is known as cyclical outcomes - outcomes that vary depending on the ordering of presentation of choices - when voters preferences are not single peaked. See Duncan Black, "On the Rationale of Group Decision Making" 194856 Journal of Political Economy 133; and Anthony Downs An Economic Theory of Democracy (Harper Row, New York, 1957).

42 The decision about the desired government intervention (eg expenditure or regulation) depends on the individual's perceived benefits from the intervention and her expected share of any cost (eg in taxes or forgone output) for a given level of intervention. For the median voter's choice to be efficient, however the sum of all the benefits across all voters from an intervention must be equal to the marginal cost of the intervention. Further each individual's cost shares must be adjusted so the cost price is equal to the benefits she perceives from the level of intervention chosen by the median voter. Any divergence will tend to lead to inefficiency. A further source of inefficiency arises when the voting population does not coincide with the tax paying population. 
that the state is made up of individuals subject to the same limitations as private economic actors.

Indeed the problem arising from the bounded rationality of individuals may be more significant when one considers central decision making or planning. Even assuming central planners are as rational or more rational than others in the economy, a number of problems are likely to undermine the efficacy of central decision making. Given the typically economy-wide effects of government actions, and the complexity of the problem solving state decision makers are expected to engage in, more severe demands may be placed on their bounded rationality than is the case for private planning.

Centralised decision making will also face major information disabilities. The information relevant to a central planning decision may be hard to obtain. The information relevant will typically be diverse, and may include unavailable information on consumer preferences, or alternative production technologies, or alternative ways of organising activities. Alternatively information may be possessed by individuals who are difficult to locate, or be of a nature that is difficult to communicate from one agent to another. If information is difficult to transfer then this means that it will be difficult to both acquire information at the centre relevant to decisions to be made, and then disseminate that information from the centre to the agents who are to carry out plans. The information costs underlying centralised decision making therefore militate against its successful execution. It is likely to be based on incomplete information with consequent adverse effects.

In a decentralised setting individuals accept risks, make judgements and adapt to unexpected occurrences, with those who are caught out suffering the consequences of their mistakes, and those who adopt successful strategies benefiting. There are thus strong incentives for individuals to seek out successful strategies, with successful strategies being likely to survive, thereby benefiting the system. In comparison with central planning, mistakes tend to be costly and impact on everyone, with few alternatives being available when things go wrong. The only safeguard is conscious and purposive policy review. Incentives to undertake this effectively however, in order to conserve on scarce resources may generally be weak within the state, given the fact that state decision makers may not bear all the costs of poor decisions. The state's ability to tax may mean its decision-makers do not really face the true cost of resources with consequences for its use of resources and for other sectors in the economy. Similarly when it regulates or owns resources or organisations its incentives to efficiently monitor the effects of these policies on the use of scarce resources may be weak.

The incentive problems undermining decision making in 'the state' in relation to property rights go deeper than this however. We have already noted that opportunism creates incentive problems for private arrangements. Opportunism in the context of central government decision-making and planning may exhibit itself in the form of political favours, 
featherbedding and waste of public resources. These problems are fundamental to an evaluation of the most suitable level and form of centralised state decision making in a society. The mechanisms through which opportunism and incentive problems generally work in the state are in fact more subtle and complex than are widely appreciated.

On the one hand definitions of property rights impact on the overall growth of the economy, on the other hand they impact on the rents accruing to particular groups. If coalitions of individuals can either gain direct control of the property rights defining power of the state or bargain with the state to change property rights (for example Federated Farmers, Business Roundtable, the trade union movement) then they can affect the value of their property rights, or acquire better rights (through tariffs, taxation, subsidies or legislation).

From the redistributive societies of ancient Egyptian dynasties, through Greek and Roman times, to the medieval manor, there was a persistent tension between the ownership structure that maximised the rents to the ruler or particular groups, and an efficient and equitable system that encouraged economic growth and social equity. ${ }^{43}$ The dominance of agriculture in the western world prior to the nineteenth century resulted in struggles to control the state being associated with the distribution of landed wealth and income. Over more recent time, changes in the dominant interests within society, and the growth of pluralism have been associated with the radical changes in relative prices stemming from the Industrial Revolution. These changes have generated different outcomes in terms of property rights conflicts. The decline in the relative importance of land rent (and the landlord), the growth of manufacturing and services, and the growing share of income going to labour, transformed the structure of production and created new interest groups.

Property rights conflicts may appear more subtle now that they are largely not associated with tangible resources like land, and also more complex given a pluralistic society. The nature of the interventions affecting the value and distribution of property rights are also far more developed including taxation, government expenditure, regulation and legislation. However conflicts of interest and the state's role in resolving them are no less critical to the efficiency and equity of our economy than earlier ones. The state is a double edged sword. It can pursue generally accepted social goals or it can be diverted to pursuing the interests of particular groups.

In general government policy faces the danger of two types of capture:

43 D C North Structure and Change in Economic History (WN Norton, New York, 1981) for an analysis of economic history from an institutional perspective. 
(a) Capture from external sources - that is, lobby groups; ${ }^{44}$

(b) Capture from internal sources - that is, its own bureaucracy. ${ }^{45}$

The mechanisms of policy capture and safeguards against it need to be continually reviewed.

One of the clear ways through which inappropriate policy may result from external capture lies in the differential effects of policies on people. Frequently benefits are concentrated on particular groups while the costs of the policy may be dispersed. This sets up a dynamic process where those who benefit from the policy find it easier to organise and lobby for its introduction and maintenance, while those who bear the costs of the policy find it too difficult to organise an effective opposition.

The relation between a government and its own bureaucracy on the other hand can be described as a bilateral monopoly. It can be suggested however that the relation favours the bureaucracy, that elected representatives are at a disadvantage in relation to their own bureaucracy simply because of an information asymmetry. ${ }^{46}$ The problem that the bureaucracy may hold better information about how government services actually operate creates the potential for opportunism by the bureaucracy including shirking, budget maximisation and generally inefficient policies for society as a whole.

Thus the main factors that will influence the extent, nature and outcome of central government intervention in New Zealand are:

(a) the nature of representative government adopted, including the powers of the executive and its relationship to Parliament, and questions relating among other things to a Bill of Rights and the electoral system; and

(b) the structure, organisation and accountability of the civil service

Propositions about what services the government ought to finance are reduced in relevance in the absence of an analysis of how the above system actually performs. Similarly however questions about how the government should deliver whatever services are deemed necessary require an assessment of the way government delivery actually works, what are the pressures exerted upon it - what are the constraints, the relationships between action and outcome, and the preferences underlying government activities. For

44 For a formal model of interest group lobbying and references see Becker, "A Theory of Competition Among Pressure Groups for Political Influence" (1983) 98 Quarterly Journal of Economics 371.

45 See W Niskanen Bureaucracy and Representative Government (Aldine, Chicago, 1971) for a seminal economic analysis of this point. 
example what are the consequences of maximising behaviour on the part of economic agents within the government's bureaucracies.

A comparative systems analysis on government itself would distinguish the effect of alternative institutional arrangements on incentives and information and thus on behaviour at two levels:

(a) the political institutions which express the preferences for public services;

(b) the bureaucratic or other state organisations which supply these services.

The integration of these two elements, or the process of exchange between these institutions, how it is structured and conducted is a further focus of attention. The key element here is the nature of the relation and the implications of this for management systems.

\section{Conclusion}

The analysis of government and government policy needs to be based on a comparative institutional approach. This approach invites assessing alternative institutional structures (both private and governmental) according to the processes and outcomes they involve, utilising generally accepted criteria for making social choices. This will require in depth consideration of the goals of our society and of the means to achieve them. In comparing different means or institutions one should assess primarily:

(a) their efficiency implications by examining in particular:

(i) the incentives they create;

(ii) their effect on the efficient use of information;

(iii) the evolutionary or dynamic adaptability characteristics of the institution; and

(b) their equity implications by examining:

(i) their effect on the opportunities of individuals;

(ii) their effect on the fairness of outcomes;

(iii) their effect on the fairness of processes.

A comparative systems approach is "level headed" about the limits of government, and the limits of private arrangements, eschews the blind pursuit of ideal worlds by recognising trade-offs between goals, and places emphasis on a detailed microanalytic approach or, simply, attention to detail including empirical evidence and argument. The comparative systems approach to policy formation moreover suggests that there may be little one can say 
about the appropriate "level" of government involvement in the economy, whether it should be more or less, without conducting a comparative systems analysis in every area of policy.

The comparative approach to formulating policy then involves two steps. Firstly identify the objectives and rationale of government policy with an emphasis on identifying clearly the nature of the problems it seeks to address. Any claimed problem with private arrangements should be subjected to detailed scrutiny. In the past the limits of private contracting have often been overstated. The need for empirical research, or information and analysis of private arrangements that may deal with perceived problems is central. It should not be assumed for example that particular groups are not competent to look after their own interest without some convincing evidence that extends beyond anecdotal observation. Further, every perceived problem should be subjected to detailed analysis as to its causes. For instance, claims that there are divergences between social and private costs are not useful ways to express many perceived problems.

Secondly it is not sufficient to establish that a problem exists; it is also essential to establish that government can improve things. The essential element in policy formulation is therefore a detailed comparative systems approach. This comparative analysis needs to be based on an evaluation of the full impact of a government policy over time and its consequent impact on other areas of the economy. This suggests the need to avoid partial analysis of policy interventions and to adopt a more critical attitude to the likely hidden or secondary effects of any policy, given the problems of interdependencies repeatedly pointed to in this paper.

In the design of policy, a comparative institutional approach moreover suggests that attention should focus on minimising the problem of "government failure". Tendencies for governments to fail in the achievement of generally accepted objectives and for them to pursue other objectives can it suggests be reduced; although not eliminated, by institutional design based on a comparative systems analysis of the way the government organises itself.

In undertaking this analysis the basic principles to keep in mind are:

(a) Clarify objectives: It is important that the objectives underlying any particular area of government activity are clear.

(b) Transparency: There is a need to ensure that there is transparency not only in the objectives being pursued but also the means by which objectives are to be achieved. This implies for instance the need to make explicit possibly hidden subsidies.

(c) Avoidance of capture: There is a need to minimise scope for the capture of government policy when designing both the structure and processes used to formulate and deliver government policy. 
(d) Incentives: There is a need to ensure incentives on individuals in the state are aligned to the achievement of government goals.

(e) Information: It is important that efficient use is made of information, and that the costs of information are adequately recognised.

(f) Accountability: The design of incentive and information systems should attempt to enhance accountability of the government's agents to their principals namely Ministers and ultimately the electorate.

(g) Contestability: Where possible in order to enhance both incentives and the efficient use of information, contestability of both policy advice and service delivery should be encouraged, either externally or internally.

Noble and clear objectives are not all that is needed for a government to perform well. It also requires a clear understanding of the nature and effects of its policy instruments and of the potential and the limitations of both private arrangements and central control. 